Anthony H. Maister MB CHB(UCT) FFARCs(E)

\title{
Atrial fibrillation following physostigmine
}

The side effects of physostigmine, a tertiary amine anticholinesterase agent commonly used to treat postanaesthetic depression caused by a large number of drugs. are thought to be fairly mild. A case is reponed in which atrial fibrillation followed a total dose of $2 \mathrm{mg}$ of this drug to a patient who was siow in recovering from a general anaesthetic. The arrythmia was self-limiting and required no therapy. Indications and precautions for the use of physostigmine are discussed.

\section{Key words}

ANTAGONISTS, MISCELLANEOUS: physostigmine, HEART: arrhythmia, atrial fibrillation.

Physostigmine is a tertiary amine anticholinesterase that readily crosses the blood-brain barrier and is therefore frequently used to treat the central anticholinergic syndrome or central nervous system depression caused by a variety of drugs. ${ }^{1}$ Muscarinic effects such as nausea, vomiting, and bradycardia are commonly seen, but atrial fibrillation in the perioperative period has not been reported following its use. The following is a case in which this rare occurrence was documented.

\section{Case report}

A 55-year-old female with squamous carcinoma of the cervix presented for insertion of a Fletcher suit with afterloader for radium implantation. Two months prior to the present admission the patient had undergone a partial thyroidectomy for a follicular adenoma. At that time her $\mathrm{T}_{3}$ and $\mathrm{T}_{4}$ levels were within normal limits but her TSH level was

From the Department of Anesthesiology, Harbor UCLA Medical Center, 1000 W. Carson Street, Torrance, California 90509. elevated and this was thought to indicate a failing thyroid gland. The patient's premedicant drugs at that time were meperidine $50 \mathrm{mg}$, hydroxyzine $50 \mathrm{mg}$, and glycopyrrolate $0.4 \mathrm{mg}$, all IM. One hour later, anaesthesia was induced with thiopenta] and maintained with enflurane ( 1 per cent), $\mathrm{N}_{2} \mathrm{O}$ (50 per cent) and $\mathrm{O}_{2}$. The operation lasted four hours and at completion of surgery Naloxone $0.1 \mathrm{mg}$ was given IV with no obvious improvement. She was taken to the recovery room intubated and was finally extubated three hours later. Postoperatively she was discharged home on thyroid hormone suppression therapy of synthroid $0.2 \mathrm{mg}$ daily. She also received radium therapy for her cervical carcinoma.

At present admission the patient was emaciated and weighed $44 \mathrm{~kg}$. Blood pressure was 90/60 torr; heart rate was 70 beats/min. Serum sodium concentration was $142 \mathrm{mEq} \cdot \mathrm{L}$; potassium $4.5 \mathrm{mEq} \cdot \mathrm{L}$, and hematocrit was 36.5 per cent. Her electrocardiogram (EKG) showed a normal sinus rhythm with a rate of 70 beats/min with possible nonspecific subepicardial injury. The chest $x$-ray was normal. The only medication at this time was Synthroid $0.2 \mathrm{mg}$ and the patient appeared to be clinically euthyroid.

Premedication was with meperidine $50 \mathrm{mg}$ and hydroxyzine $25 \mathrm{mg}$, both IM one hour prior to induction. Preinduction the patient was well sedated and was responsive to questions and commands. Anaesthesia was induced with thiopental $150 \mathrm{mg}$ in divided doses, and maintained with $\mathrm{O}_{2}$ two litres per minute, $\mathrm{N}_{2} \mathrm{O}$ four litres per minute, and halothane ( 1 per cent). She received further increments of thiopental, to total dose of $325 \mathrm{mg}$. Blood pressure and heart rate remained at $90 / 60$ torr and 65 beats/min respectively. The total anaesthesia time was $75 \mathrm{~min}$. At the end of the procedure the patient was taken to the recovery room where the blood pressure was $105 / 70$ torr, the heart rate was 80 beats/min and the EKG showed normal sinus rhythm. After remaining in the recovery room for 3 


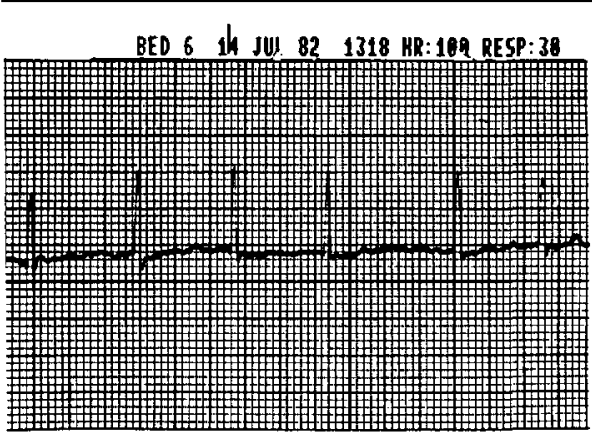

FIGURE 1 Atrial fibrillation, with ventricular rate of about $100 / \mathrm{min}$. Onset following administration of physostigmine.

hours the patient was still very drowsy but was breathing adequately. Her axillary temperature on admission to the recovery room was $96^{\circ} \mathrm{F}$ and this rose slowly to $97.5^{\circ} \mathrm{F}$ with the use of warming blankets and overhead heating lamps. In an attempt to reverse the residual effects of the earlier general anaesthetic and the sedation caused by the premedicant hydroxyzine, physostigmine was given in divided doses over five minutes to a total dose of $2 \mathrm{mg}$. The patient immediately became nauseous and vomited, and shortly thereafter developed atrial fibrillation as demonstrated in Figure 1. The QRS rate was 100 beats/min. The fibrillation lasted for only 90 seconds and then reverted spontaneously to normal sinus rhythm (Fig. 2). A 12-lead EKG shortly afterwards revealed a sinus tachycardia of 100 beats/ $\mathrm{min}$ but was otherwise unchanged from the preoperative tracing. The patient remained drowsy and was only discharged to her ward three

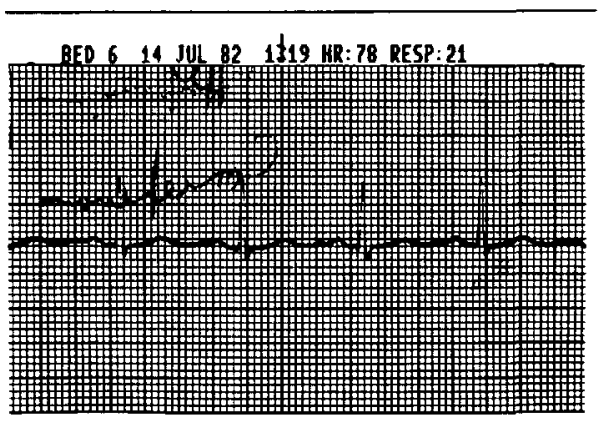

FIGURE 2 Retum of normal sinus rhythm (see text). hours later. She had an uneventful postoperative course and was discharged home on the second postoperative day.

\section{Discussion}

The central anticholinergic syndrome ${ }^{2}$ is characterized by confusion, agitation, restlessness, hallucinations, dysarthria, ataxia, delirium stupor and coma. It can be caused by a variety of compounds and is best treated with physostigmine which is thought to be a nonspecific analeptic. Flacke and Flacke $^{l}$ have grouped drugs which cause the syndrome into: (1) tricyclic antidepressants, (2) antipsychotics including chlorpromazine, droperidol, ${ }^{3}$ and hydroxyzine, (3) antihistamines, and (4) drugs such as diazepam, ${ }^{4}$ lorazepam, and narcotic analgesics which have no anticholinergic activity but which have been reported to be antagonized by physostigmine. Physostigmine has also been shown to reverse somnolence following general anaesthesia, ${ }^{5}$ scopolamine ${ }^{6}$ used as premedication and has been used to prevent the delirium caused by ketamine. $^{7}$

The severity of the muscarinic side effects of anticholinesterases are related to the dose, route, and speed of administration. The commonest cardiovascular side effect is bradycardia ${ }^{3.5}$ due to increased vagal tone at the sinoatrial node. The action of physostigmine on the heart is complex as it both shortens the refractory period of cardiac muscle fibres and increases the refractory period and conduction time of the conducting tissues. Its action at any given moment will reflect the sum of the excitatory and inhibitory actions of accumulated acetylcholine at different sites in the heart. ${ }^{8}$ For this reason it is advisable that physostigmine be used with caution in patients with cardiovascular disease. With physostigmine these side effects are generally not very severe and therefore the routine prior administration of glycopyrrolate or atropine is not recommended. Other side effects such as increasing salivation, nausea and vomiting increase with increasing dose but are fairly infrequent with physostigmine doses of $1 \mathrm{mg} .{ }^{6}$ This is not the case with neostigmine or edrophonium.

In the case described, the occurrence of the atrial fibrillation was unexpected. No therapy was needed because the arrhythmia only lasted 90 seconds before spontaneously reverting to normal sinus rhythm. The mechanism by which the fibrillation 
occurred can only be surmised to have been due to severe vagal depression of both the S-A and the A-V nodes. This allowed a latent re-entrant focus to emerge within the atrial myocardium. The slow ventricular response most likely reflects depression of A-V nodal conduction which might in turn be attributed to enhanced vagal tone or to an intrinsic conduction defect. As the vagal tone decreased, the $\mathrm{S}-\mathrm{A}$ node once again became the pacemaker and normal sinus rhythm returned.

The rationale for the use of physostigmine following the second anaesthetic was based upon the knowledge that naloxone, although used only in small dosage, had not been very beneficial in the reversal of the postoperative sedation following that anaesthetic and for which the patient had received similar premedication. In addition, it was felt that hydroxyzine $50 \mathrm{mg}$ can commonly cause this degree of sedation in this patient population and it was therefore worthwhile to attempt to reverse this aspect of the sedation. Following the arrhythmia and the nausea it was felt that the patient should not be given any naloxone and that she be allowed to recover spontaneously. The only other report of serious arrythmias following physostigmine describes the occurrence of atrial fibrillation with frequent premature ventricular contractions and occasional ventricular tachycardia following the intravenous "push" of physostigmine $2 \mathrm{mg}$ to a healthy 20 -year-old male intoxicated with Jimson weed seeds. 9

In conclusion, an unusual and potentially harmful side effect of physostigmine has been observed during an unsuccessful attempt to reverse postanaesthesia somnolence. One must be aware that in a patient with cardiovascular disease the effects produced by this drug may be quite severe, as has previously been described. We recommend that, apart from having anticholinergics at hand, the heart rate should be closely monitored and drugs necessary to treat other potentially dangerous arrhythmias should be available when physostigmine is used.

\section{Ackrowledgements}

I would like to thank Dr. Chingmuh Lee and Dr. Marc Weller for their help in reviewing this article and Paula $\mathrm{M}$. Conley for her secretarial assistance.

\section{References}

1 Flacke JW, Flacke W. Cholinergic and anticholinergic drugs. Dnug Interactions in Anesthesia. Edited by Smith NT, Miller Rd, Corbasier AN, Philadelphia, Lea and Feliger, 1981. Pp. 113-28.

2 Longo VG. Behavioral and electroencephalogram effects of atropine and related compounds. Pharmacology Rev, 1966; 18: 965-96.

3 Bidwai AV, Cornelius $L R$, Stanley $T H$. Reversal of innovar-induced postanesthetic somnolence and disorientation with physostigmine. Anesthesiology, 1976; 441: 249-52.

4 Bidwai AV, Stanley $T H$, Rogers C, Riet, EK. Reversal of Diazepam induced postanesthetic somnolence with physostigmine. Anesthesiology, 1979;51: 256 .

5 Hill GE, Stanley TH, Senker CR. Physostigmine reversal of postoperative somnolence. Can Anaesth Soc J, 1977; 24: 707 .

6 Holzgrafe RE, Vondrell JJ, Mintz SM. Reversal of postoperative reactions to scopolamine with physostigmine. Anesth Analg, 1973; 52: 921.

7 Balmer HGR, White SR. Antagonism of ketamine by physostigmine. Br J Anaesth, 1977; 49: 510 .

8 Goodman and Gillman. The Pharmacologic Basis of Therapeutics. Third Edition. Macmillan Press, p. 451.

9 Levy R. Arrythmias following physostigmine administration in Jimson Weed Poisoning. JACEP, 1977; 6: 107 .

\section{Résumé}

Les effets secondaires de la physostigmine, amine tertiaire à activité anticholinestérasique utilisée pour traiter la dépression post-anesthésique sant considérés comme mineurs. On rapporte ici un cas de fibrillation auricutaire à la suite d'une dose totale de $2 \mathrm{mg} d u$ médicament administrée do un malade dont le réveil était retardé. L'arrythmie s'est résolue spontanément et n'a nécessité aucune thérapie. L'auteur discute des indications et des précautions à prendre lorsqu' on utilise la physostigmine. 